\title{
Meet the Lemons: An Experiment on How Cheap-Talk Overcomes Adverse Selection in Decentralized Markets
}

\author{
Simon Siegenthaler ${ }^{\mathrm{a}, *}$ \\ ${ }^{a}$ New York University Abu Dhabi, P.O. Box 129188, Abu Dhabi, United Arab Emirates.
}

\begin{abstract}
We report on an experiment on decentralized markets in the presence of adverse selection. When allowing for costless and non-binding communication (cheap-talk), there exists a partially separating equilibrium that results in a substantially higher efficiency than the adverse selection benchmark. The partially separating equilibrium hinges on the presence of matching frictions, which create a trade-off for low quality sellers between successfully mimicking high quality sellers and an increased matching probability if they truthfully reveal their type. The experimental results reflect the theoretical predictions of the partially separating equilibrium: communication is informative and improves efficiency compared to the benchmark without cheap-talk. We conduct control treatments to show that truth-telling is not explained by lying aversion or pro-social preferences, but is due to the pecuniary incentives of the partially separating equilibrium.
\end{abstract}

Keywords: Adverse Selection, Cheap-Talk, Decentralized Markets, Experiment, Frictions, Information Transmission, Market for Lemons

JEL: C78, C91, D82, D83

\section{Introduction}

In the presence of adverse selection, prices may fail to allocate goods optimally and markets operate at inefficient levels (Akerlof, 1970). A wide range of institutions has been proposed to retrieve at least part of this loss in surplus. Examples include signaling devices, for instance warranties and ecolabels, or screening devices such as deductibles and aptitude tests. While these institutions restore the functioning of markets, they also require agents to engage in socially costly activities 1 This is no coincidence, as we know from Samuelson (1984) that under adverse selection there is no mechanism that attains first-best efficiency. Reducing informational asymmetries thus necessitates costs on a different margin.

While this conclusion implies that signaling or screening costs are required for information revelation in markets with perfect competition, it does not imply the same in the presence of frictions. Markets with frictions operate at an inefficient level even if informational problems are eliminated, and thus Samuelson's result does not exclude the possibility to overcome informational inefficiencies without introducing another type of cost. In fact, an intriguing finding due to Kim (2012) states

\footnotetext{
*Email address: s.siegenthaler@gmail.com.

${ }^{1}$ For instance, there are significant costs associated with running assessment centers, including labor, physical space, and people's time. Similarly, labels have no economic value besides functioning as a signal to consumers.
} 
that free and non-binding communication (cheap-talk) suffices to substantially mitigate adverse selection in decentralized markets - where exchange of goods is typically characterized by search or matching frictions, e.g. labor markets (Mortensen and Pissarides, 1994) 2

This paper is concerned with an experimental test of the prediction that cheap-talk alleviates information problems in markets with frictions. Consider the following market. Goods can be of two qualities: high or low. Each seller owns one unit of a good and is informed about its quality. Buyers are uninformed. Each buyer selects a seller, offering her a price in exchange for the good. It is possible that several buyers select the same seller and that some sellers do not receive any offer. This represents a simple way of introducing matching frictions (see e.g. Satterthwaite and Shneverov, 2007). Finally, the sellers accept their preferred offer, if any. If communication is possible, the market is augmented with an initial stage in which each seller announces a quality - not necessarily the true quality. Buyers then observe all messages and select a seller based on the announced qualities.

With the possibility to send messages, this game has a partially separating equilibrium with endogenous market segmentation: a submarket in which only lemons sell coexists alongside a market in which high quality goods are sold with positive probability. Some low quality sellers truthfully reveal their type, despite the strong incentives to misrepresent information usually associated with market environments. To see why, notice that in the market segmentation equilibrium buyers have two options: offering to a seller who truthfully announces to be of the low quality, or offering to a seller who claims to own a high quality good but who may be lying. When offering to the latter, buyers risk to obtain a low quality good at a high price. Buyers may also offer a low price, but then they face the risk to be matched with a high quality seller who rejects low offers. These risks are not present when approaching a seller who reveals to be of the low quality. As a consequence, competition among buyers will be stronger in the lemons submarket. Hence, for low quality sellers truth-telling has the benefit of entering the submarket which attracts more buyers. This compensates for the forgone opportunity to potentially extract high prices when mimicking high quality sellers. Frictions are crucial. If sellers were free to choose among all price offers, truthtelling would not affect the degree of competition. Sellers would try to fully exploit their information advantage, resulting in the familiar market breakdown due to adverse selection. Communication is also crucial. If agents cannot send messages, high quality goods are not traded.

The experiment consists of four treatments. In each treatment we implement a series of markets consisting of six buyers and six sellers. Our main treatment Communication First (CF) implements the market as described above. Given the complexity of the partially separating equilibrium, it is a priori difficult to assess whether subjects will behave in the predicted way. Moreover, there are many other equilibria, including pooling equilibria in which messages are uninformative. Which equilibrium is played is an empirical question. This motivates the experimental approach. It is interesting to note that the market segmentation equilibrium is selected by a criterion called no incentive to separate (NITS) suggested in Chen et al. (2008) 3

One of the main challenges in the experiment is to separate the mechanism of market segmen-

\footnotetext{
${ }^{2}$ For another interesting case where cheap-talk affects equilibrium play in (bilateral) bargaining, see Farrell and Gibbons (1989).

${ }^{3}$ In the present setting, an equilibrium satisfies NITS if low quality sellers prefer the equilibrium outcome to credibly revealing their type, if they somehow could. NITS does not lead to a unique equilibrium prediction, but it excludes all babbling equilibria. See Dickhaut et al. (1995), Blume et al. (2001), Kawagoe and Takizawa (2009) and De Groot Ruiz et al. (2014) for experimental tests of different cheap-talk equilibrium selection criteria.
} 
tation from truth-telling due to non-standard preferences. Indeed, there is a rich experimental literature establishing that private information is often communicated truthfully despite monetary incentives to lie - an observation that is attributed to pro-social preferences, lying aversion or guilt aversion. Important contributions include Gneezy (2005), Charness and Dufwenberg (2006), Vanberg (2008), Sutter (2009), and Charness and Dufwenberg (2011) 4 The approach taken in this article complements this literature by testing a mechanism in which communication alleviates adverse selection even if assuming pure payoff maximization 5 To isolate the effect of market segmentation, we conduct a control treatment Matching First (MF), in which the timing of the cheap-talk messages and the matching decisions is reversed: buyers are first matched to a seller, then sellers send messages. Theoretically, market segmentation breaks down in MF, because by design sellers cannot attract more buyers by revealing their quality. On the other hand, if truth-telling is based on non-standard preferences, it should be irrelevant whether communication happens before or after the matching of agents.

In addition, we implemented treatment Matching First II (MF II) which is identical to MF, except that buyers can only see the message sent by their matched seller. The aim of MF II is to create an environment where lying aversion is most likely to induce trade. In MF a buyer may not believe the message of his matched seller, if he realizes that the observed set of messages is inconsistent with the known distribution of low and high quality sellers in the market. In MF II, this effect is eliminated because each buyer observes only one message.

In the fourth treatment No Communication (NC), sellers cannot send messages. The treatment serves as an interesting benchmark case. Comparing $\mathrm{NC}$ to $\mathrm{CF}$ allows us to observe the welfare-improving effect of cheap-talk in markets with matching frictions and adverse selection. The theoretical predictions are the same in MF, MF II and NC (under standard preferences). Comparing $\mathrm{NC}$ to the MF treatments, we can thus learn more about the effects of cheap-talk in absence of the market segmentation mechanism.

The experimental results show that behavior in $\mathrm{CF}$ closely follows the theoretical predictions of the partially separating equilibrium. Messages are informative, market segmentation is observed frequently and rates of trade and welfare are high. In contrast, welfare is low in MF and MF II. In fact, average efficiency is not different from the one observed in NC, where sellers cannot send messages. These results show that non-standard preferences such as lying or guilt aversion are by themselves insufficient to induce trade of high quality goods. The effectiveness of cheap-talk in alleviating informational problems is based on the monetary incentives of the partially separating equilibrium 6

It is important to note that market segmentation is not a coordination device, in the sense that it improves the matching technology. The opposite is true: there are fewer meetings between

\footnotetext{
${ }^{4}$ See also Vallev et al. (1998), Valley et al. (2002), Croson et al. (2003), Lundquist et al. (2009), Charness and Dufwenberg (2010) and Erat and Gneezv (2012). Cai and Wang (2006) focus on bounded rationality as an explanation for "overcommunication".

${ }^{5}$ Another important difference is that the present article explores markets, whereas the mentioned studies employ bilateral settings. Goeree and Zhang (2014) introduce competition to the model of Charness and Dufwenberg (2011). See also Cadsby et al. (1990), Holt (1995) and Forsythe et al. (1999).

${ }^{6}$ The results of MF and MF II do not exclude the possibility that lying or guilt aversion facilitate the high efficiency in CF. To check for this, we elicited subjects' lying aversion and find that the lying aversion measure correlates with truth-telling in $\mathrm{CF}$ and MF. Interestingly, this points to a further advantage of market segmentation: while lying aversion exists in $\mathrm{CF}$ and $\mathrm{MF}$, it only affects outcomes when buyers can choose sellers conditional on the observed messages.
} 
buyers and sellers in the partially separating equilibrium of $\mathrm{CF}$ than in the pooling equilibria of MF, MF II and NC. This observation holds in theory and is confirmed in the experimental data. The efficiency improvements of market segmentation are thus due to a reduction in informational asymmetries.

Many real-world markets fit well with the model tested in this experiment. Recall the underlying intuition of the partially separating equilibrium: low quality types forfeit their information advantage to reduce matching frictions in their submarket by attracting more buyers. An example of this are non-binding list prices, as often observed for used cars or housing. High list prices tend to induce a smaller number of interested buyers. Brokers may thus restrain from overstating asking prices, consistent with the market segmentation equilibrium 7 Costless advertising serves as another example. If sellers can make costless and unverifiable claims, one might think that advertising is ineffective in conveying information. Would sellers not always overstate the quality of their products? Our model suggests that they may not, if announcing a lower quality leads to more potential buyers (who however buy at lower prices). In the presence of frictions, low quality sellers have an incentive to be truthful. Finally, the setting can be interpreted as a competing auctions framework. Indeed, the buyers' bidding stage corresponds to a first-price auction with an unknown number of competitors. Kim and Kircher (2015) study competing auctions with cheap-talk. Their examples are also relevant in our context: messages may represent asking prices in online marketplaces, an intended budget in procurement auctions, an announced wage range when posting job openings or a verbal description of the value of a job.

Explanations other than market segmentation can be at play to rationalize the above examples. Advertisement may be a costly signal rather than cheap-talk (Nelson, 1974). Non-binding list prices have often been interpreted as ceiling prices, in which case they have a commitment value (Chen and Rosenthal, 1996). Our experiment abstracts from these alternative explanations and asks whether the market segmentation equilibrium based on cheap-talk can be observed in the lab. The fact that our results are in line with the theoretical predictions provides evidence that endogenous market segmentation via communication is an important determinant of behavior in many real-world environments as well.

The remainder of the article is organized as follows. The next section introduces the model. Section 3 presents the experimental setting and design, including a set of predictions that will guide our empirical analysis. The experimental results are reported in Section 4. Finally, Section 5 concludes.

\section{Theoretical Background}

\subsection{Model}

There are $n_{B}>1$ buyers and $n_{S}>1$ sellers interacting in a market for an indivisible good. Each seller can sell at most one unit and each buyer wants to buy at most one unit of the good. Goods are available in two qualities. There are $n_{H}$ sellers that can sell a high $(\mathrm{H})$ quality good and $n_{L}$ sellers that can sell a low $(\mathrm{L})$ quality good. A seller of type $\theta=\{L, H\}$ has a reservation cost of $c_{\theta}$. A good of quality $\theta$ yields a value of $v_{\theta}$ to the buyer. We assume positive gains from trade for both qualities, i.e., $v_{\theta}>c_{\theta}$ for $\theta=L, H$.

\footnotetext{
${ }^{7}$ The example is also consistent with our model in that non-binding list prices tend to correlate with final prices (see Kim, 2012).
} 
Denote the fraction of low quality sellers by $\hat{q}=n_{L} / n_{S}$. The focus is on markets in which adverse selection is severe: high quality goods do not trade in a pooling equilibrium. This requires that the buyers' expected value falls short of the high quality sellers' cost 8

$$
\hat{q} v_{L}+(1-\hat{q}) v_{H}<c_{H}
$$

The trading process is as follows. First, sellers simultaneously send messages $m \in\{l, h\} 9$ Messages are cheap-talk and do not involve direct costs. We will say that sellers who send message $l$ are in submarket $l$ and sellers who send message $h$ are in submarket $h$. Second, each buyer observes the number of sellers in each of the two submarkets. Each buyer then chooses a seller to whom he makes a take-it-or-leave-it offer. Offers are made simultaneously and several buyers may select the same seller. This implies that some sellers may not receive an offer. Third, each seller who receives at least one offer decides whether to accept or reject the offer(s). A seller can accept at most one offer. A buyer whose offer $p$ is accepted earns $v_{\theta}-p$ if the quality of the good is $\theta$. A seller of type $\theta$ who accepts a price $p$ earns $p-c_{\theta}$. Buyers and sellers who do not trade earn 0 .

\subsection{Equilibrium Characterization}

We focus on Sequential Equilibrium à la Kreps and Wilson (1982). In any equilibrium, sellers accept the highest offer that covers their production costs in the last stage of the game. We take this as given and describe a seller strategy by a probability $\alpha(\theta)$ to send message $l$ depending on the realized type $\theta$. Buyers can distinguish sellers only on the basis of messages. Thus, each buyer effectively chooses a submarket $l$ or $h$. Let us describe a submarket by $m_{k}$, where $m=\{l, h\}$ denotes the message and $k$ the number of sellers in the submarket. Let $\beta\left(m_{k}\right)$ be the probability that a buyer chooses submarket $m_{k}$. Let $S$ be the set of possible submarkets. Buyers' bidding strategies are then described by a cumulative distribution function $F: \Re_{+} \times S \rightarrow[0,1]$ where $F\left(p, m_{k}\right)$ is the probability that a buyer offers a price not larger than $p$ to a seller in submarket $m_{k}$.

There exist babbling equilibria in which messages do not carry information. For instance, it is part of an equilibrium if sellers send message $l$ and $h$ each with probability 0.5 and buyers randomize their choice of a seller, independently of the observed messages. The next observation highlights that there is also a symmetric partially separating equilibrium 10

Observation 1. Given a mild condition guaranteeing sufficient competition between sellers, there exists a symmetric (partially) separating equilibrium in which $\alpha(L)>0$ and $\alpha(H)=0$.

The intuition of the result is as follows. Because buyers face no quality uncertainty in submarket $l$, they will be relatively more likely to join submarket $l$ than submarket $h$. As a consequence, the expected number of offers a seller receives is larger in submarket $l$ and thus matching frictions for a seller are lower in the submarket consisting of low messages. This advantage of submarket

\footnotetext{
${ }^{8}$ Inequality (1) is sufficient but not necessary to prevent trade of high quality goods in the pooled market. As will be shown, the trading process implies imperfect competition and buyers may prefer to offer low prices even if their expected profit from offering $c_{H}$ is positive.

${ }^{9} \mathrm{~A}$ richer message space is conceivable, for instance announcing non-binding selling prices. However, binary messages are without loss of generality if there are only two qualities. For more on this see Kim (2012).

${ }^{10}$ For the partially separating equilibrium to exist, we need to rule out markets in which simultaneously the number of low quality sellers is low and the surplus from trading the low quality good is small. In particular, both $n_{L} / n_{S}-\left(n_{L}-1\right) /\left(n_{S}-1\right) \leq\left(v_{L}-c_{L}\right) /\left(v_{H}-v_{L}\right)$ and $v_{L}-c_{L}<v_{H}-c_{H}$ are independently sufficient for the proof of Observation 1
} 
$l$ compensates low quality sellers for the forgone opportunity to extract high prices in submarket $h$. The discussion of the experimental setting in the next section will provide a derivation of the partially separating equilibrium.

The next observation concerns a variant of the above game that will be important for the experimental predictions of the control treatments. Suppose that the timing of messages and matching decisions is reversed, such that (1) each buyer first chooses a seller, (2) sellers send messages, (3) buyers observe all messages and make an offer to their selected seller, and (4) sellers accept or reject the offer(s) they received. We refer to this setting as Matching First (MF), as opposed to Communication First (CF) in our main specification 11

Observation 2. In the Matching First game all symmetric equilibria are pooling, i.e. price offers are strictly below $v_{L}$ and high quality sellers never trade.

Recall that in a partially separating equilibrium low quality sellers are truthful because the number of offers they receive tends to be higher in submarket $l$ than in submarket $h$. Since in setting MF a seller's expected number of offers is fixed before she sends her message, low quality sellers strictly prefer to not reveal their type if message $h$ triggers an offer above $c_{H}$ with positive probability. Hence, the only symmetric equilibria that exist are pooling equilibria in which high quality sellers do not trade. A proof is given in the appendix.

Observations 1 and 2 focus on symmetric equilibria. Formally, this requires $\beta\left(m_{k}\right)$ to be the same across buyers for each submarket and $\alpha(\theta)$ to be the same across sellers of the same type. This is a common assumption in the literature, as exchange in large markets is usually considered to be anonymous. We will however also account for the possibility that subjects may coordinate on equilibria in asymmetric strategies.

\section{The Experiment}

\subsection{The Setting}

Consider a market with six buyers and six sellers. There are three low quality sellers and three high quality sellers. Parameters are given by $v_{H}=19, c_{H}=14, v_{L}=5$ and $c_{L}=0$. Notice that the expected value for buyers in the pooled market is 12, falling short of the high quality sellers' cost. Without market segmentation, high quality goods do not trade.

We have chosen a surplus of 5 for both qualities. There is an equal number of buyers and sellers and an equal number of low and high quality sellers. These choices were made to exclude to possibility that subjects focus on one submarket based on asymmetries in the experimental setting. However, as shown in Observation 1, the partially separating equilibrium identified in the following exists under a wide range of parameter constellations, e.g. if one side of the market is larger or the generated surplus differs across qualities.

\subsection{The Partially Separating Equilibrium}

We next derive the (symmetric) market segmentation equilibrium for the experimental parameters. In the last stage of the game, sellers trivially choose the highest price that covers their production costs. If there is no such offer, the seller rejects all offers.

\footnotetext{
${ }^{11}$ For the following result, we assume that buyers' optimal offers exceed $c_{H}$ with positive probability, if they are in a submarket consisting of all high quality sellers and a single low quality seller.
} 
Figure 1: Predicted Cumulative Distribution of Buyer Offers

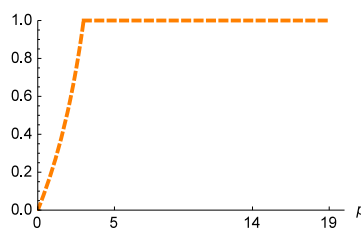

(a) $h_{6}$

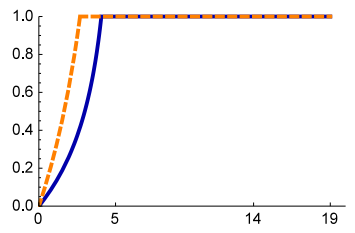

(b) $\left\{l_{1}, h_{5}\right\}$

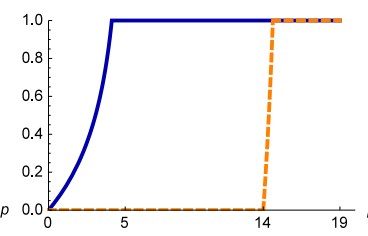

(c) $\left\{l_{2}, h_{4}\right\}$

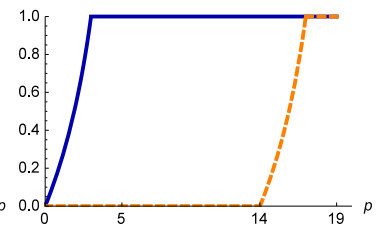

(d) $\left\{l_{3}, h_{3}\right\}$

The figure depicts the theoretical CDF of buyer offers in the four market structures that are observed with positive probability in equilibrium. The solid line depicts the CDF for submarket $l$; the dashed line for submarket $h$.

Consider the behavior of buyers. Because in the partially separating equilibrium we have $\alpha(L)>$ 0 and $\alpha(H)=0$, buyers observe four possible market structures: the pooled market $h_{6}$ in which all six sellers chose to send message $h$, the intermediate market structures $\left\{l_{1}, h_{5}\right\}$ and $\left\{l_{2}, h_{4}\right\}$, and the fully separated market $\left\{l_{3}, h_{3}\right\}$. For the observed market structure, buyers choose $\beta\left(m_{k}\right)-\mathrm{a}$ submarket to enter - and $F\left(p, m_{k}\right)$ - what price to offer.

The key insight when deriving $F\left(p, m_{k}\right)$ is that the lowest price offer chosen by a buyer must be either $c_{L}=0$ or $c_{H}=14$. To see why, observe that $F\left(p, m_{k}\right)$ cannot have an atom in its support, because otherwise deviating to a slightly higher offer increases the probability to win at a negligible cost. Buyers thus mix over an interval of prices. A buyer who chooses the lowest offer on this interval is sure to lose whenever he has a competitor. This implies that the lowest offer is optimal conditional on being the only buyer matched to the respective seller. Depending on the buyer's belief about the composition of sellers in the chosen submarket, the offer is thus either 0 or 14 . The exact range of offers and the corresponding mixing probabilities follow by the requirement that the buyer must be indifferent between the lowest offer and any higher offer in the support of $F\left(p, m_{k}\right)$, until at some price $\bar{p}$ we have $F\left(\bar{p}, m_{k}\right)=1$.

Buyers also choose submarkets. As long as there is a sufficient number of buyers, it is not profitable for buyers to enter one of the submarkets with probability 1 (in a symmetric equilibrium). We thus have $\beta\left(m_{k}\right) \in(0,1)$ for all $m_{k} \neq h_{6}$. Recall that the monopsonist offer is optimal in each of the submarkets. To calculate expected payoffs, one therefore needs to find the probability a given buyer is the only one offering to his respective seller. For submarket $m_{k}$, the probability is $\lambda\left(m_{k}\right)=\sum_{i=0}^{n_{B}-1} \beta\left(m_{k}\right)^{i}\left(1-\beta\left(m_{k}\right)\right)^{n_{B}-1-i}\left(\begin{array}{c}n_{B}-1 \\ i\end{array}\right)(1-1 / k)^{i}$. Consider market structure $\left\{l_{1}, h_{5}\right\}$. The expected payoff in $l_{1}$ is $\lambda\left(l_{1}\right) *(5-0)$. The expected payoff in $h_{5}$ is $\lambda\left(h_{5}\right) * 0.4 *(5-0)$, where 0.4 is the probability to be matched with a low quality seller. Equalizing the expected payoffs in both submarkets, one obtains $\beta\left(l_{1}\right)=0.29$ and $\beta\left(h_{5}\right)=0.71$. Along the same lines, we obtain $\beta\left(l_{2}\right)=0.59, \beta\left(h_{4}\right)=0.41$ and $\beta\left(l_{3}\right)=0.5, \beta\left(h_{3}\right)=0.5$.

It is interesting to note that the expected fraction of buyers to sellers is 1.72 in $l_{1}$ versus 0.86 in $h_{5}$, and 1.77 in $l_{2}$ versus 0.62 in $h_{4}$. This makes the buyers' trade-off apparent: while in submarkets $h$ buyers face quality uncertainty, submarkets $l$ are characterized by stronger buyer competition. For the fully separated market structure, there is no quality uncertainty and hence buyers enter each submarket with $50 \%$ probability.

Figure 1 depicts the resulting cumulative distribution of price offers for our parameters. Figure $1 \mathrm{a}$ shows the pooled market. Here the fraction of low quality sellers is $50 \%$ and buyers offer low prices ranging between 0 and 3 . This is a situation where adverse selection precludes trade 
of high quality goods. The same applies to both submarkets of the partially separated market structure $\left\{l_{1}, h_{5}\right\}$ shown in Figure $1 \mathrm{~b}$. In particular, note that in $h_{5}$ the buyers' expected value of $0.4 * 5+0.6 * 19=13.4$ still falls short of the high quality sellers' cost. In contrast, offers exceed $c_{H}=14$ in submarkets $h$ of the partially separated market $\left\{l_{2}, h_{4}\right\}$ in Figure $1 \mathrm{c}$ and the fully separated market in Figure $1 \mathrm{~d}$.

It remains to check whether the assumed seller strategies $\alpha(L)>0$ and $\alpha(H)=0$ are optimal. Because message $l$ reveals a seller to be of the low quality, it is always (weakly) optimal for high quality sellers to enter submarket $h$. Are low quality sellers willing to reveal their type? Let $U_{L}\left(m_{k}\right)$ be a low quality seller's expected payoff in submarket $m_{k}$. Given the buyers' strategies, we compute $\left\{U_{L}\left(l_{k}\right)\right\}_{k=1}^{3}=\{2.75,2.84,1.32\}$ and $\left\{U_{L}\left(h_{k}\right)\right\}_{k=4}^{6}=\{6.87,1.03,1.32\}$. We can see that a low quality seller prefers the lemons submarket $l_{1}$ over the pooled market $h_{6}$. The best outcome for a low quality seller is to be in submarket $h_{4}$, because low quality goods are sold at high prices. In equilibrium, the expected benefit of the information advantage in submarket $h$ equals the improved matching probability in submarket $l$. This holds at $\alpha(L)=0.4812$

\subsection{Asymmetric Equilibria}

An interesting question is whether there exist asymmetric partially separating equilibria, in addition to the babbling equilibria and the symmetric partially separating equilibrium identified above. We mention two types of equilibria in asymmetric strategies. Fix the sellers' acceptance decisions and the buyers' submarket and offer decisions to be the same as in the symmetric market segmentation equilibrium. In the first type of equilibrium, some sellers always choose message $h$, independent of their type. The remaining sellers increase their probabilities to send message $l$ relative to the symmetric equilibrium.

- Let seller $i$ choose $\alpha_{i}(L)=\alpha_{i}(H)=0$. For all sellers $j \neq i$, let $\alpha_{j}(L)=0.62$ and $\alpha_{j}(H)=0$. Choosing submarket $h$ is optimal for seller $i$, because the other sellers play message $l$ with a larger probability than in the symmetric market segmentation equilibrium. All other sellers are indifferent between submarkets: competition is reduced in submarket $l$, because seller $i$ joins submarket $h$, but this effect is offset by an increase in the probability to join submarket $l$ for the other sellers in the market. There is also an equilibrium in which two sellers always send message $h$ and the remaining four players choose $\alpha(L)=0.89$.

In the second type of equilibrium, some sellers always choose message $l$ and the remaining sellers decrease their probabilities to send message $l$ if they are type $L$, relative to the symmetric equilibrium.

- Let seller $i$ choose $\alpha_{i}(L)=1$ and $\alpha_{i}(H)=0$. For all sellers $j \neq i$, let $\alpha_{j}(L)=0.37$ and $\alpha_{j}(H)=0$. Choosing submarket $l$ is optimal for seller $i$, because the other sellers play message $l$ with a smaller probability than in the symmetric market segmentation equilibrium. All other sellers are indifferent between submarkets: the increase in competition in submarket $l$ if seller $i$ joins submarket $l$ for sure is offset by the lower probability to join submarket $l$ of the sellers other than seller $i$. There is also an equilibrium in which two sellers always send message $l$ and the remaining four players choose $\alpha(L)=0.21$.

\footnotetext{
${ }^{12}$ The equilibrium value of $\alpha(L)$ satisfies $\sum_{i=0}^{n_{L}-1} \alpha(L)^{i}(1-\alpha(L))^{n_{L}-1-i}\left(\begin{array}{c}n_{L}-1 \\ i\end{array}\right) U_{L}\left(l_{i+1}\right)=\sum_{i=0}^{n_{L}-1} \alpha(L)^{i}(1-$ $\alpha(L))^{n_{L}-1-i}\left({ }^{n_{L}-1}{ }_{i}\right) U_{L}\left(h_{n_{S}-i}\right)$.
} 
Table 1: Experimental Design

\begin{tabular}{lllll}
\hline Treatment & Ses. & N & Messages & Matching \\
\hline CF & 6 & 72 & Observed by all buyers & Buyers choose submarket $^{*}$ \\
MF & 4 & 48 & Observed by all buyers & Random $^{* *}$ \\
MF II & 4 & 48 & Observed by matched buyer & Random \\
NC & 4 & 48 & No messages & Random \\
\hline
\end{tabular}

* Buyers choose a submarket $(l$ or $h)$ and are randomly matched to a seller in this submarket.

** Buyers are randomly matched to one of the six sellers.

The preceding examples demonstrate the richness of the equilibrium set. However, the underlying intuition of endogenous market segmentation is the same in the symmetric and asymmetric partially separating equilibria. Interestingly, we will show in the results section that some experimental markets indeed seem to be characterized by asymmetric strategies 13

\subsection{The Experimental Design}

The experimental design consists of four between-subject treatments. The treatments are summarized in Table 1. The main treatment Communication First (CF) implements the main model introduced in Section 2 for the experimental parameters. In treatment No Communication (NC) sellers cannot send messages to buyers, but otherwise the setting is identical. NC thus serves as our benchmark for a situation in which adverse selection prevails. The theoretical implications for efficiency and payoffs are shown in Table 2 .

Notice that in the experiment, buyers did not choose a specific seller. Instead in CF buyers chose a submarket $l$ or $h$ after observing the sellers' messages. They were then randomly assigned to a seller in the chosen submarket 14 Likewise, in treatment NC, buyers make offers to a randomly assigned seller in the pooled market. The matching procedure was carefully explained to the subjects, and in each period it was explicitly mentioned that everybody has now been randomly matched.

In the light of the experimental literature on cheap-talk and hidden information, differences in behavior between $\mathrm{CF}$ and $\mathrm{NC}$ could also stem from subjects' preferences to tell the truth or from fairness concerns. To address this possibility, we implement treatments with cheap-talk, but in which all (symmetric) equilibria are pooling. This is achieved by reversing the order of the matching and cheap-talk stage. In particular, in treatments Matching First (MF) and Matching First II (MF II), buyers are first randomly matched to a seller and then sellers send messages. Buyers either observe all six messages (MF) or they observe only the message sent by the seller

\footnotetext{
${ }^{13}$ It is noteworthy that there is also an asymmetric equilibrium that allows for trade of high quality goods in the MF setting, illustrating that Observation 2 does not hold if we drop the anonymity assumption. Consider the following behavior: $\alpha(H)=0$ for all sellers, $\alpha(L)=0$ for sellers $1,2,3$ and 4 and $\alpha(L)=1$ for sellers 5 and 6 . There will always be at least four sellers in submarket $h$ - the three high quality sellers and at least one low quality seller. Sellers 5 and 6 can never hope for high offers when joining submarket $h$ (buyers do not offer high prices in $h_{5}$ ), and hence send message $l$. For sellers 1 to 4 , message $h$ is strictly optimal, due to the positive probability to be the only low quality seller in $h_{4}$. Note that this is not an equilibrium in the CF setting, because low quality seller would strictly prefer sending message $l$.

${ }^{14}$ Random matching within submarkets avoids the problem that buyers may choose a seller based on how the choice is presented, e.g. a buyer could always choose the seller displayed on the left-hand side of the screen.
} 
with whom they are matched (MF II). In the absence of non-standard preferences, the endogenous market segmentation equilibrium breaks down in MF and MF II, and the theoretical predictions coincide with the ones for $\mathrm{NC}$ (see Observation 21). On the other hand, if sellers are averse to lying or have pro-social preferences, messages may still be informative. A comparison between CF and MF will thus allow us to say more about the source of the efficiency gains in CF. MF II was introduced as a further control treatment to give lying aversion its best shot. In MF buyers observe all messages and may therefore be exposed to message distributions that are inconsistent with truth-telling whenever there are not three $l$ and three $h$ messages. Buyers may then be reluctant to believe the message of their own seller. If buyers only observe the message of the seller they are matched with, attempts at truth-telling by some sellers cannot be frustrated as easily.

The experiment was run in December 2013 and January 2014 at the experimental laboratory of the University of Bern. In total 216 students participated in the experiment, mainly from business administration and economics. The data consists of 18 session, each with twelve participants. We used the z-Tree software developed by Fischbacher (2007). Sessions lasted between 50 and 80 minutes and average earnings were 32 CHF including a show-up fee of 14 CHF 15

Upon arrival at the lab, subjects were randomly assigned to a computer terminal and were given time to read the instructions. The instructions are provided in the online appendix. To ensure everyone understands the instructions, subjects had to fill out a set of control questions. A brief verbal summary of the setting was given. Subjects were then randomly assigned to be one of the six buyers or one of the six sellers. Roles were fixed throughout the experiment. Subjects played 20 periods. In each period, there were three high and three low quality sellers, but the quality of individual sellers randomly changed between periods. Each seller was informed about her quality at the beginning of each period. Buyers only knew that there are three sellers of each type. Interactions were anonymous and there were no identifiers that would allow subjects to know or guess with whom they interact in different periods.

Following the main part of the experiment, we elicited subjects' lying aversion using a task adapted from Gneezv (2005). Information on subjects' loss aversion was also gathered. At the beginning of the experiment, subjects were informed that there would be two additional parts, but no details were explained until the first part was completed. We will describe the auxiliary tasks in Section 4.2 and 4.3.

\subsection{Theoretical Predictions}

Table 2 summarizes the theoretical predictions of the key outcome variables. The predictions for CF (Communication First) assume the symmetric partially separating equilibrium derived in Section 3.2. The predictions for NC (No Communication) are for the model without messages. The NC predictions are the same as for the babbling equilibria in CF. They also correspond to the predictions for MF (Matching First) and MF II (Matching First II), in which matching takes place before the cheap-talk stage.

Table 2 shows that endogenous market segmentation $(\mathrm{CF})$ significantly increases rates of trade and efficiency compared to a setting without cheap-talk (NC) or with cheap-talk but without the possibility to choose sellers based on messages (MF treatments). It is remarkable that cheap-talk leads to trade with high quality sellers without undermining trades with low quality sellers. We can also see that expected payoffs in CF are higher than in the other treatments for all agents.

\footnotetext{
${ }^{15}$ At the time the experiments were conducted, 1 US Dollar corresponded roughly to $0.91 \mathrm{CHF}$.
} 
Table 2: Theoretical Predictions

\begin{tabular}{|c|c|c|c|c|c|c|c|c|c|}
\hline & \multirow[b]{2}{*}{$\alpha(L)$} & \multicolumn{2}{|c|}{ Rates of Trade } & \multicolumn{3}{|c|}{ Ex Ante Efficiency } & \multicolumn{3}{|c|}{ Payoffs } \\
\hline & & $\mathrm{L}$ & $\mathrm{H}$ & Total & $\mathrm{L}$ & $\mathrm{H}$ & Buyer & Seller L & Seller H \\
\hline $\mathrm{CF}$ & 0.48 & 0.70 & 0.25 & 14.26 & 10.57 & 3.69 & 1.04 & 2.46 & 0.21 \\
\hline $\mathrm{NC}$ & - & 0.67 & 0.00 & 9.98 & 9.98 & 0.00 & 1.00 & 1.32 & 0.00 \\
\hline MF / MF II & {$[0,1]$} & 0.67 & 0.00 & 9.98 & 9.98 & 0.00 & 1.00 & 1.32 & 0.00 \\
\hline
\end{tabular}

The predictions for $\mathrm{CF}$ are for the symmetric partially separating equilibrium. The predictions in $\mathrm{NC}, \mathrm{MF}$ and MF II are the same. In MF and MF II, $\alpha(L) \in[0,1]$, as messages are uninformative. Ex ante efficiency is measured as the average surplus generated with each seller type ( $\mathrm{L}$ and $\mathrm{H}$ ). Total efficiency is the sum over both types.

If all sellers trade, total welfare would be 30 . First-best efficiency is however not the appropriate benchmark. Due to the frictions of the matching process, the first-best outcome is not attainable even with complete information. In fact, we cannot go beyond expected trading rates of $67 \%$ for both types of sellers simultaneously, which would lead to an expected welfare of 19.95 . The ex ante efficiency of 14.26 therefore constitutes a substantial improvement over the pooled market with an efficiency level of 9.9816

\section{Results}

The discussion of the experimental results is organized around three questions: (1) Do we observe endogenous market segmentation? If yes, (2) does market segmentation increase rates of trade and efficiency? We would also like to understand whether the results are based on the proposed mechanism or if and to what extent truth-telling is due deviations from the assumption of pure payoff maximization: (3) are the results driven by non-standard preferences?

We only use observations from periods 11-20. The qualitative results are unaffected if all observations are included, but the treatment differences are more pronounced in later periods when subjects have settled on an "equilibrium" behavior. All non-parametric statistical tests are based on session averages as the unit of observation. We will use the Wilcoxon rank sum test for comparisons across treatments and the Wilcoxon matched-pairs signed-ranks test for within treatment comparisons.

\subsection{Market Segmentation, Rates of Trade and Efficiency}

We start our discussion with the following result, which provides an answer to question (1) above.

Result 1 (Endogenous Market Segmentation). Behavior in CF is consistent with endogenous market segmentation. Messages are informative and frequently induce market structures that permit

\footnotetext{
${ }^{16}$ The ex ante efficiency of 14.26 is below the efficiency reached in a centralized market without frictions, but in which adverse selection prevails (there all low quality goods would trade, implying an efficiency of 15). This is however not a general feature of the model. There are examples in which adding matching frictions raises efficiency relative to the centralized market benchmark.
} 
Figure 2: Sellers' Messages and Market Segmentation

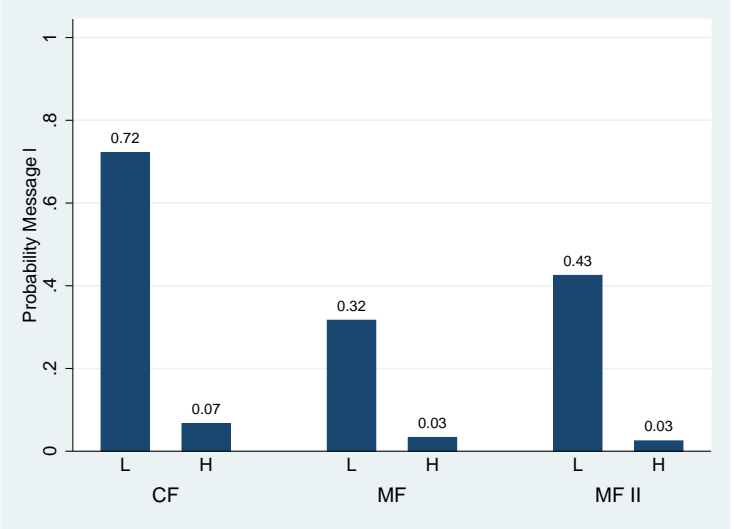

(a) Messages

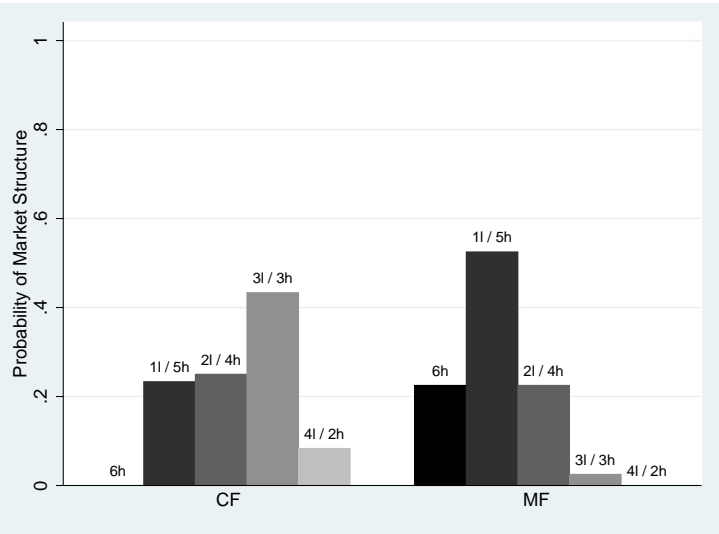

(b) Market Segmentation

Figure (a) depicts the probability of a seller to send message $l$, separated by treatment and seller type. Figure (b) shows the distribution of realized market structures (message sets) in CF and MF.

trade with high quality sellers. Low quality sellers are willing to forgo high prices in submarket $h$, because by revealing their quality they on average attract twice as many offers.

Figure 2a shows that messages are a good predictor of a seller's true type in CF. High quality sellers almost always send message $h(93 \%)$. This observation is important, because it allows buyers to meaningfully interpret low quality sellers' behavior. The figure further shows that low quality sellers reveal their quality $72 \%$ of the time in CF. Low quality sellers are significantly more likely to send message $l$ in treatment CF than in MF and MF II $(\mathrm{p}=0.01)$. The difference between MF and MF II is not significant $(\mathrm{p}=0.19)$. Moreover, low quality sellers' probability to reveal their type in $\mathrm{CF}$ is significantly higher than the theoretically predicted $48 \%(\mathrm{p}=0.03)$.

Buyers observe a range of different submarkets in $\mathrm{CF}$ as well as MF. Figure 2b depicts the frequency of the different market structures. The most common market structure in $\mathrm{CF}$ is $3 l / 3 h$, observed in more than $43 \%$ of the cases. In $85 \%$ of the cases this market structure corresponds to the completely separated market, i.e. all low quality sellers send message $l$ and all high quality sellers send message $h$. In the remaining 15\%, submarket $l$ contains two low quality and one high quality seller. In contrast, in MF the most prominent set of messages is $1 l / 5 h(52 \%)$ and complete separation is almost never observed. Note that in $2 l / 4 h$ high quality goods are also expected to be traded, implying that the observed market structures theoretically allow for trade with high quality sellers in $68 \%$ of the cases in CF and in $25 \%$ of the cases in MF. In MF II the probability that a seller who sends message $h$ is of the high quality is $0.97 /(0.97+0.57)=0.63$. This translates into an expected value of 13.82, falling short of high type sellers' reservation cost. Hence, even if we interpret message $l$ in MF (32\%) and MF II (43\%) as truth-telling rather than babbling, not enough information is revealed to consistently generate trade with high quality sellers.

Low quality sellers' incentive to reveal their quality in CF stems from their ability to attract more buyers in submarket $l$. In CF low quality sellers receive on average 1.47 offers when sending message $l$ and only 0.74 offers when sending message $h(\mathrm{p}=0.03)$. Figure $3 \mathrm{a}$ depicts the buyers' choice between submarkets. In the completely separated market structure, buyers distribute almost evenly 
Figure 3: Participation and Matching

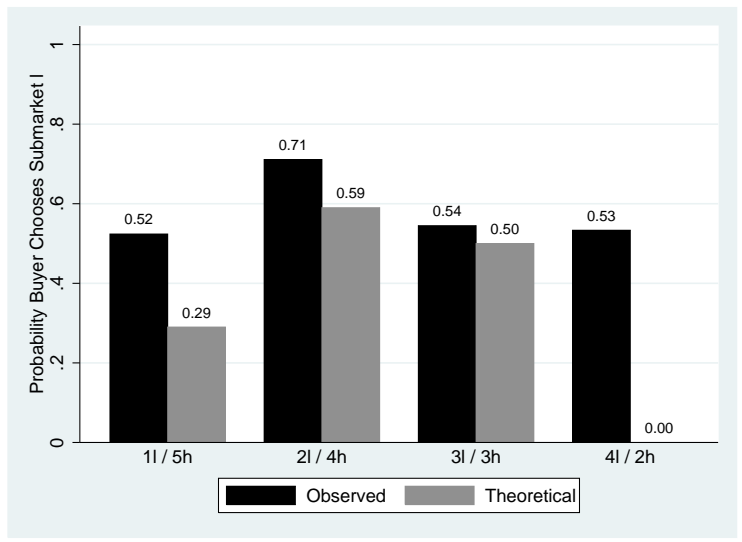

(a) Buyers' Participation Decision in CF

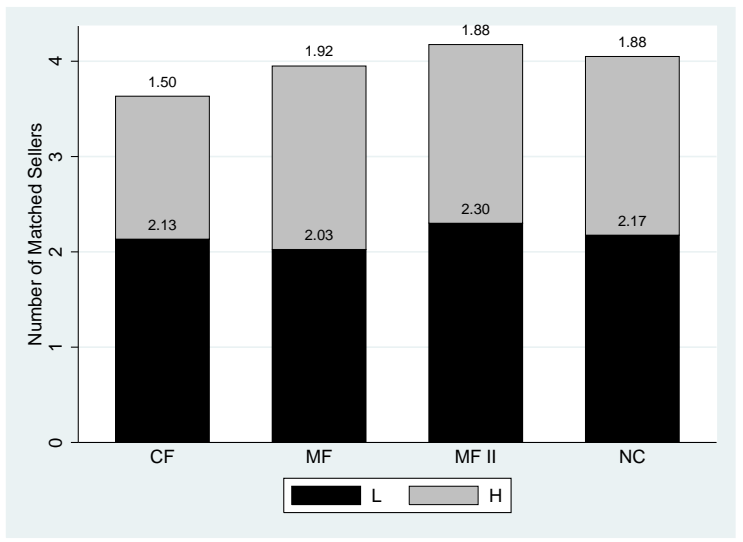

(b) Matching

Figure (a) depicts the fraction of buyers who joined submarket $l$ for each market structure as well as the corresponding theoretical predictions. Figure (b) shows the average number of sellers (per period) matched with at least one buyer, separated by $\mathrm{L}$ and H-type sellers.

among the two submarkets. The difference to the theoretical prediction of $\beta\left(l_{3}\right)=\beta\left(h_{3}\right)=0.5$ is not significant $(\mathrm{p}=0.43)$. This is remarkable, because buyers do not seem to fear losses in submarket $h$ of $3 l / 3 h$ and consider the two submarkets as equally attractive. For the other market structures, buyers are biased towards submarket $l$, beyond the theoretically expected bias. We will show in Section 4.2 that this can be explained by loss aversion.

Let us sidestep a potential pitfall. It is tempting to think of the market segmentation mechanisms implemented in CF as a coordination device in the sense that matching becomes more efficient. However, the opposite is true: the buyers' possibility to choose between submarkets introduces a distortion. Buyers enter the lemons submarket with a larger probability than what would be optimal in terms of the induced number of meetings. Figure $3 \mathrm{~b}$ shows that the average number of sellers that receive at least one offer is around 4 for treatments MF, MF II and NC and 3.63 for CF. The number of meetings is not significantly different across treatments for low quality sellers. On the other hand, high quality sellers encounter significantly fewer meetings in CF than in the other treatments $(\mathrm{p} \leq 0.06)$. Hence, market segmentation negatively affects the number of buyer-seller meetings.

To complete the discussion on Result 1, we look at sellers' messages on the individual level. In Section 3.3, we have mentioned the existence of asymmetric equilibria. Our discussion so far is not conclusive as to how the aggregate probabilities of sending message $l$ are generated across sellers. A closer look reveals that the majority of low quality sellers chooses to mix their messages. However, in all six session of CF there is also at least one seller who always chooses message $l$ as a low type. Consistent with the asymmetric equilibria, the effect of truthful sellers is typically balanced by other sellers who misrepresent their type more often than the predicted $52 \%$. The probabilities to send message $l$ as a low quality seller for the six sellers in the different sessions are $(0.40,0.75,0.80,0.83,1,1),(0.25,0.67,0.71,0.75,0.83,1),(0.40,0.43,0.67,0.67,0.67,1),(0.17$, $0.67,0.80,1,1,1),(0,0.17,0.60,1,1,1),(0.33,0.75,0.88,1,1,1)$. Note that for periods $11-20$, 
Figure 4: Cumulative Distribution of Buyer Offers

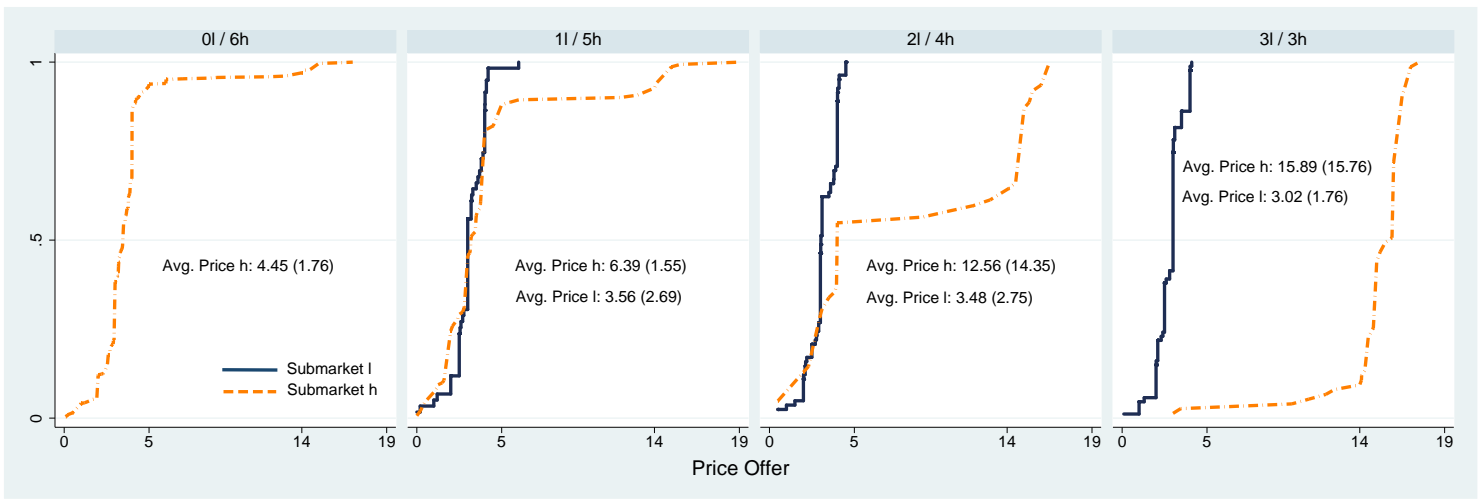

Empirical cumulative distribution of offers for submarkets $l$ and $h$ and the corresponding average trading prices (theoretical predictions for $\mathrm{CF}$ in parentheses). Observations are pooled across treatments. Observations of $\mathrm{NC}$ and MF II are reflected in the first quadrant.

each seller was at least twice in the role of a low quality seller and most sellers between four and six times. We conclude that the symmetric equilibrium does not fully accurately describe behavior on the individual level. Notice, however, that market segmentation in the asymmetric equilibria occurs for the same reasons as in the symmetric prediction 17

The fact that endogenous market segmentation was common is not sufficient to improve the efficiency of a market. In addition, this requires that buyers offer prices that exceed the high quality sellers' reservation cost of 14 in submarkets $h$ of $3 l / 3 h$ and $2 l / 4 h$. Figure 1 depicts the empirical cumulative distribution of buyers' offers for each market structure observed in equilibrium. Observations are pooled across treatments. In particular, offers that were made in treatment NC, MF II and the $0 l / 6 h$ market structures of $\mathrm{CF}$ and MF are summarized in the first subfigure. All of these instances represent pooled markets, where the messages do not separate sellers 18 As theoretically predicted, offer distributions were not significantly different in these four markets. For the same reason, offers in market structures $1 l / 5 h, 2 l / 4 h$ and $3 l / 3 h$ are pooled across treatments $\mathrm{CF}$ and MF. Note that almost all cases of market structure $1 l / 5 h$ occurred in MF, and almost all cases of market structure $3 l / 3 h$ occurred in $\mathrm{CF}$ (see Figure 2b).

In accordance with theory, offers in submarket $h$ of market structure $3 l / 3 h$ exceed 14 . The same applies to half of the offers in submarket $h$ of $2 l / 4 h$. In both market structures, the average offer in submarket $h$ is significantly larger than the average offer in submarket $l(\mathrm{p} \leq 0.02)$. In Section 4.2,

\footnotetext{
${ }^{17} \mathrm{~A}$ related question is whether truth-telling in CF could be triggered by the repetition of the game for 20 periods. Several pieces of evidence suggest that this was not the case. First, building up reputation was impossible as buyers and sellers had no identifiers. Second, even though the market consisted of the same twelve subjects in all periods, a buyer is matched with only one seller in each period and hence the probability to be matched with the same seller in two consecutive periods is small. Repeated game equilibria are thus unlikely to emerge. Third, if the results in $\mathrm{CF}$ were driven by repetition, the same should also apply to $\mathrm{MF}$, but there we do not observe market segmentation. Finally, behavior is relatively stable across periods and in particular we do not observe an end game effect.

${ }^{18}$ In MF II the distribution of offers does not depend on the observed message, according to a two-sample Kolmogorov-Smirnov test $(\mathrm{p}=0.2)$.
} 
Table 3: Descriptive Statistics

\begin{tabular}{|c|c|c|c|c|c|c|c|c|}
\hline & \multicolumn{2}{|c|}{ Rate of Trade } & \multicolumn{3}{|c|}{ Efficiency } & \multicolumn{3}{|c|}{ Payoffs } \\
\hline & $\mathrm{L}$ & $\mathrm{H}$ & $\mathrm{L}$ & $\mathrm{H}$ & Total & Buyer & $\mathrm{L}$ & $\mathrm{H}$ \\
\hline $\mathrm{CF}$ & $\begin{array}{l}0.70 \\
(0.70)\end{array}$ & $\begin{array}{l}0.32 \\
(0.25)\end{array}$ & $\begin{array}{l}10.50 \\
(10.57)\end{array}$ & $\begin{array}{l}4.83 \\
(3.69)\end{array}$ & $\begin{array}{l}15.33 \\
(14.26)\end{array}$ & $\begin{array}{l}0.64 \\
(1.04)\end{array}$ & $\begin{array}{l}3.27 \\
(2.46)\end{array}$ & $\begin{array}{l}0.56 \\
(0.21)\end{array}$ \\
\hline MF & $\begin{array}{l}0.67 \\
(0.67)\end{array}$ & $\begin{array}{l}0.09 \\
(0.00)\end{array}$ & $\begin{array}{l}10.00 \\
(9.98)\end{array}$ & $\begin{array}{l}1.37 \\
(0.00)\end{array}$ & $\begin{array}{l}11.37 \\
(9.98)\end{array}$ & $\begin{array}{l}0.06 \\
(1.00)\end{array}$ & $\begin{array}{l}3.58 \\
(1.32)\end{array}$ & $\begin{array}{l}0.10 \\
(0.00)\end{array}$ \\
\hline MF II & $\begin{array}{l}0.77 \\
(0.67)\end{array}$ & $\begin{array}{l}0.03 \\
(0.00)\end{array}$ & $\begin{array}{l}11.75 \\
(9.98)\end{array}$ & $\begin{array}{l}0.38 \\
(0.00)\end{array}$ & $\begin{array}{l}11.88 \\
(9.98)\end{array}$ & $\begin{array}{l}0.47 \\
(1.00)\end{array}$ & $\begin{array}{l}3.00 \\
(1.32)\end{array}$ & $\begin{array}{l}0.03 \\
(0.00)\end{array}$ \\
\hline $\mathrm{NC}$ & $\begin{array}{l}0.72 \\
(0.67)\end{array}$ & $\begin{array}{l}0.04 \\
(0.00)\end{array}$ & $\begin{array}{l}10.75 \\
(9.98)\end{array}$ & $\begin{array}{l}0.62 \\
(0.00)\end{array}$ & $\begin{array}{l}11.37 \\
(9.98)\end{array}$ & $\begin{array}{l}0.57 \\
(1.00)\end{array}$ & $\begin{array}{l}2.62 \\
(1.32)\end{array}$ & $\begin{array}{l}0.04 \\
(0.00)\end{array}$ \\
\hline
\end{tabular}

Efficiency is given by the average per period surplus generated with each seller type. Total efficiency is the sum over both types. Payoffs are the average earnings per period and subject. Theoretical predictions are given in parentheses.

we will show that the split between low and high offers in submarket $h$ of $2 l / 4 h$ can be explained by loss aversion, both theoretically and in the experiment. Also in accordance with theory, offers are below $v_{L}=5$ in the lemons submarkets and submarket $h$ of market structure $1 l / 5 h$. We conclude that buyers' bidding behavior reflects the informational content of the messages well. This leads to our second result, providing an answer to question (2) stated at the beginning of the section.

Result 2 (Rates of Trade and Efficiency). Rates of trade with high quality sellers and efficiency are significantly higher in CF than in MF, MF II and NC, and not significantly different from the theoretical predictions.

Table 3 presents observed rates of trade, efficiency and average payoffs of buyers and sellers. The theoretical predictions are given in parentheses. The trade frequency of high quality sellers is negligible for treatments MF II and NC, $9 \%$ for MF and 32\% for treatment CF. The trade frequency for high quality sellers is significantly higher in CF than in all other treatments $(p=0.01)$. The trade frequency with high quality sellers in $\mathrm{CF}$ is also higher than the predicted $25 \%$, but this difference is not significant $(\mathrm{p}=0.11)$. Trade frequencies with high quality sellers are not different between MF, MF II and NC ( $>>0.21)$. For low quality sellers, the trade frequency is around $70 \%$ for all treatments and differences are insignificant for all comparisons, except that low quality sellers trade more often in MF II than in CF $(\mathrm{p}=0.08)$ and MF $(\mathrm{p}=0.04)$.

Efficiency in $\mathrm{CF}$ is significantly higher than in all other treatments $(\mathrm{p}=0.01)$ and does not differ between treatments MF, MF II and NC ( $>00.37)$. Recall that trade failures are the only source of inefficiency in our setting. Hence, the observations on rates of trade imply that the realized surplus with high quality sellers (but not with low quality sellers) is significantly larger in CF than in the other treatments. The higher efficiency in $\mathrm{CF}$ is thus due to higher rates of trade with high quality sellers.

In $\mathrm{CF}$ the average surplus generated in a period is 15.33. This efficiency level corresponds well to the theoretical prediction $(\mathrm{p}=0.17)$. Recall that due to the matching frictions, the constrainedefficient outcome is given by a trading rate of 0.67 for both qualities, implying a surplus of 19.95 . The efficiency in CF is thus a big improvement compared to the efficiency levels in NC, MF and MF II, although welfare still falls short of the surplus in the constrained-efficient outcome $(p=0.03)$ : 
inefficiencies due to asymmetric information are not fully eliminated.

The last three columns in Table 3 show the average payoff per subject, separated by buyers and the different seller types. Buyers' payoffs fall short of the predictions in all treatments $(p<0.07)$. It is apparent that this is predominantly to the benefit of low quality sellers, who earn significantly more than expected $(\mathrm{p}<0.07)$. The differences to the theoretically expected payoffs are due to a consistent over-bidding in the lemons submarkets. A look at the average trading prices in Figure 4 confirms this. Trading prices in the pooled market or in the lemons submarkets are always above the theoretical prediction $(\mathrm{p}<0.03)$. This is reminiscent of the experimental literature on auctions and over-bidding. A range of explanations for the phenomenon have been identified, including risk aversion, noisy behavior and "joy of winning" (see Goeree et al., 2002). Our data does not allow the singling out of a particular explanation 19

The final remark on Table 3 concerns the differences in payoffs across treatment. As predicted in Table 2. CF provides a Pareto improvement over MF II and NC (but not over MF for low quality sellers). The payoff increase is strongest for high quality sellers, who are significantly better off in $\mathrm{CF}$ than in the other treatments $(\mathrm{p}<0.02)$. Notice also that buyers in MF on average barely make positive earnings and earn less than in the three other treatments $(\mathrm{p}<0.06)$. Recall that trading rates with high quality seller in MF are at $9 \%$. These attempts at trade with high quality sellers turned out to be costly for buyers.

We next turn to our third question. Can the experimental results be explained by non-standard preferences such as lying aversion, loss aversion, and pro-social behavior? The results so far have demonstrated that communication improves market outcomes in CF but not in MF and MF II. Thus, irrespective of the preferences that characterize our subjects, the market for high quality goods breaks down when switching off the monetary incentives that lead to endogenous market segmentation. This observation highlights that the buyers' possibility to choose sellers conditional on observed messages is crucial. The possibility to communicate types is not sufficient on its own. If truth-telling were based on lying aversion or concerns for fairness, one would also expect successful trade with high quality sellers in MF and MF II.

However, this does not exclude the possibility that non-standard preferences beyond pure payoff maximization act as a catalyst for market segmentation. In fact, if this is the case, this points to a further advantage of the CF setting: while cheap-talk in CF and non-standard preferences positively interact to improve market efficiency, the same does not apply to the MF settings. We focus on loss aversion and lying aversion, two behavioral deviations from the standard assumption of payoff maximization that have received considerable attention in the theoretical as well as experimental literature. The data reveals that loss aversion and lying aversion are also relevant in our setting:

Result 3 (Non-Standard Preferences). Loss aversion and lying aversion are conducive to endogenous market segmentation. Both behavioral deviations from the standard model improve the efficiency of markets in CF, but they are effectless in MF and MF II.

The following two sections provide the analysis in support of Result 3.

\footnotetext{
${ }^{19}$ Another explanation for over-bidding in our setting could be that buyers overestimate competition by other buyers, but this effect should disappear over time as buyers are informed about the number of competitors at the end of each period. Over-bidding also does not seem to be explained by the presence of sellers who demand large markups: the highest acceptable offer is rejected in only $2 \%$ of all cases. Offers may be high in anticipation of rejections, but rejection rates are close to 0 already in the first periods, indicating that the sellers' minimum acceptable offer was not a binding constraint.
} 


\subsection{Loss Aversion}

The importance of loss aversion is well-documented in the experimental literature and is typically shown to be detrimental to efficiency (Tversky and Kahneman, 1991). In contrast, the following discussion shows that loss aversion may improve the performance of the market segmentation mechanism.

\subsubsection{Theoretical Arguments}

Loss aversion captures an agent's perception that a reduction in his payoff below a certain reference point is particularly bad. The natural reference point in our setting is the no trade outcome with a payoff of 0 . Loss aversion is only relevant for buyers; sellers never accept an offer that does not cover their reservation costs. We assume constant loss aversion, as discussed in Tversky and Kahneman (1991). A buyer's utility is $v_{\theta}-p$ if $v_{\theta} \geq p$ and $\mu\left(v_{\theta}-p\right)$ otherwise, where $\theta=\{L, H\}$ and $\mu \geq 1$ is the loss aversion parameter.

Observation 3. In the market segmentation equilibrium, $\alpha(L)$ is increasing in $\mu$.

The intuition for the result is straightforward. Fix $\mu$ and recall the trade-off of low quality sellers: submarket $l$ attracts more buyers, while in submarket $h$ the seller may sell at high prices. As $\mu$ increases, potential losses in submarket $h$ receive more weight in the buyers' utility calculations. Loss averse buyers are therefore more likely to join submarket $l$ for a given market structure. The matching frictions for sellers in submarket $l$ are thus smaller for higher values of $\mu$. Therefore, more low quality sellers will choose submarket $l$ (in expectation) and market segmentation increases. Thus, anticipating that buyers are loss averse, sellers become more truthful 20 Note that the effect of loss aversion on efficiency is in general ambiguous, because buyers become less willing to offer high prices in the mixed quality submarket.

Full separation $(3 l / 3 h)$ is observed $43 \%$ of the time in treatment $\mathrm{CF}$, and price offers in submarket $h$ of $2 l / 4 h$ exceed $c_{H}=14$ in half of the cases, see Figure 4 . This behavior corresponds to the theoretical predictions with a loss aversion parameter of $\mu=1.25$. With $\mu=1.25$ the predicted probability to send message $l$ as a low quality seller is $\alpha(L)=0.71$, which is also close to the 0.72 observed in the experiment. Predicted efficiency increases from 14.26 with $\mu=1$ to 15.34 with $\mu=1.25$, the latter being close to the observed efficiency of 15.33 . We conclude that the deviations from the standard model observed in the experiment are consistent with loss aversion.

\subsubsection{Lottery Task}

To gather evidence on loss aversion, we asked subjects to complete a lottery task after the main experiment. The instructions are provided in the online appendix. Subjects were presented six lotteries, which they could either accept or decline. Each lottery gives a 50-50 chance between winning 6 CHF or losing an amount that differs between the six lotteries: 2, 3, 4, 5, 6 or 7 CHF. One of the six lotteries was randomly selected for payment. If the subject accepted the lottery, the respective earnings or losses were realized. Otherwise payoffs remained unchanged. We only discuss the results for treatment $\mathrm{CF}$, as in the other treatments high prices were rare. Almost all subjects

\footnotetext{
${ }^{20}$ Formally, to make buyers indifferent between two submarkets, $\lambda\left(h_{k}\right)$ must be strictly increasing in $\mu$ for all submarket $h_{k}$ in which high offers are made with positive probability. This requires $\beta\left(h_{k}\right)$ to decrease. The expected number of buyers in $l_{n_{S}-k}$ thus increases in $\mu$. This increases $U_{L}\left(l_{n_{S}-k}\right)$ and decreases $U_{L}\left(h_{k}\right)$, and so $\alpha(L)$ must increase to restore indifference between messages.
} 
Table 4: Loss Aversion in CF

\begin{tabular}{llll}
\hline & $(1)$ Choose submarket $l$ & $(2)$ Offer in submarket $h$ & $(3)$ Trade if H-quality \\
\hline $1 l / 5 h$ & 0.0379 & $-4.557^{* *}$ & -0.222 \\
& $(0.0915)$ & $(2.130)$ & $(0.239)$ \\
$3 l / 3 h$ & $-0.152^{*}$ & $2.085^{*}$ & -0.133 \\
& $(0.0782)$ & $(1.252)$ & $(0.133)$ \\
Loss Averse (LA) & $0.239^{* *}$ & $-6.106^{* * *}$ & $-0.463^{* * *}$ \\
& $(0.119)$ & $(2.121)$ & $(0.174)$ \\
$1 l / 5 h$ x LA & $-0.257^{* *}$ & 3.052 & 0.254 \\
& $(0.106)$ & $(2.413)$ & $(0.248)$ \\
$3 l / 3 h$ x LA & -0.0277 & $6.941^{* * *}$ & $0.548^{* * *}$ \\
& $(0.129)$ & $(2.371)$ & $(0.168)$ \\
Constant & $0.453^{* * *}$ & $10.83^{* * *}$ & $0.550^{* * *}$ \\
& $(0.131)$ & $(1.869)$ & $(0.205)$ \\
\hline$R^{2}$ (overall) & 0.070 & 0.553 & 0.188 \\
Observations & 654 & 261 & 218 \\
No. Buyers & 36 & 34 & 36 \\
\hline
\end{tabular}

${ }^{*} p<0.10,{ }^{* *} p<0.05,{ }^{* * *} p<0.01$. Random effects regression with individual-level clustered standard errors (in parentheses). Data includes all 20 periods. All estimations include period dummies. The dependent variables are (1) buyers' probability to select submarket $l,(2)$ buyers' offers in submarket $h,(3)$ buyers' probability of trade with H-quality sellers. The baseline are buyers in $2 l / 4 h$ who are not loss averse $(\mathrm{LA}=0)$.

(97\%) switch at a unique point from accepting lotteries with relatively small losses to declining all lotteries that entail larger losses. Subjects are classified as loss averse, if they only accepted the first two lotteries (losing $2 \mathrm{CHF}$ or $3 \mathrm{CHF}$ ), but not lotteries with higher losses. The results remain unchanged if we use the chosen lottery (i.e. a number between one and six) as the independent variable instead of the dummy variable. The dummy is chosen for ease of interpretation 21

Table 4 displays a set of random effects regressions on loss aversion. All periods are used for the estimations to ensure a sufficient number of observations for all submarkets. The dummy Loss Averse is equal to 1 if the subject is classified as loss averse and 0 otherwise. The baseline are buyers who are not loss averse in market structure $2 l / 4 h$. In theory, this is the only market structure in which behavior is affected by loss aversion. In column 1 , the dependent variable is a buyer's choice of a submarket $(1=l, 0=h)$. The results show that loss averse buyers are $24 \%$ points more likely to choose submarket $l$ in market structure $2 l / 4 h$. Further, recall that in submarket $h$ of $2 l / 4 h$ low as well as high price offers were made. The results in column 2 show that conditional on joining the mixed quality submarket, loss averse buyers choose lower offers than less loss averse buyers. Taken together this implies that loss averse buyers were unlikely to trade with high quality sellers in $2 l / 4 h$, which is confirmed in column 3 . The same observations are not true for market structure

\footnotetext{
${ }^{21}$ According to our classification 24 out of the 36 buyers in $\mathrm{CF}$ are classified as loss averse. Choosing a different threshold does not alter the qualitative results. The lottery task may also measure risk aversion around 0 . See Fehr et al. (2013) for a discussion. We focus on loss aversion, since (i) low quality sellers classified as loss averse were not more likely to send message $l$, which is not consistent with risk aversion and (ii) subjects' comments in the questionnaire at the end of a session indicate that buyers tried to avoid losses.
} 
$3 l / 3 h$. As predicted in theory, the impact of loss aversion on rates of trade (and thus efficiency) disappears under complete separation.

\subsection{Lying Aversion}

Following the market experiment subjects were asked to complete a lying aversion task 22 The task is adapted from Gneezy (2005). A sender communicates one of two possible messages to a receiver. The message is either "Option A will earn you a higher payoff than option B" (message A) or "Option B will earn you a higher payoff than option A" (message B). The sender is informed about the payoff consequences of both options. Senders choose a message for eight different payoff pairs. For option A they are given by $(9,11),(8,12),(7,13),(6,14),(5,15),(4,16),(3,17),(2$, $18)$, where the first entry corresponds to the sender's payoff and the second entry to the receiver's payoff. Option B triggers the same payoff pairs, except that now the receiver earns the lower amounts. Thus, message A is always the truth. Message B is the sender's preferred message in the absence of lying aversion. The monetary incentive to lie increases the more extreme the difference in payoffs becomes. The receiver is not informed about the payoff consequences of Option A and B and only observes the sender's message 23

We ran a random-effects probit regressions to examine the impact of lying aversion (not reported). The dependent variable is the probability to send message $l$ for low quality sellers. The independent variables are the treatments and the lying aversion index, given by the point at which a subject switched from message A to message B in the list of payoff pairs described above 24 We find that on average, over all treatments, a one-point increase in the lying aversion index increases the probability to send message $l$ by $4.7 \%$ points $(\mathrm{p}<0.01)$. A similar effect is observed when looking at treatments CF and MF separately. The lying aversion coefficient is insignificant in MF II ( $\mathrm{p}=0.17)$.

\section{Conclusion}

This article shows that in decentralized markets with informational asymmetries, a simple form of communication - sellers can send a costless binary message - suffices to increase efficiency substantially compared with the adverse selection benchmark. The reason is that there exists a partially separating equilibrium in which low quality sellers have an incentives to reveal their type, even if they are pure payoff maximizers. The partially separating equilibrium hinges on the presence of matching frictions, which create a trade-off for low quality sellers between successfully mimicking high quality sellers and an increased matching probability if they truthfully reveal their type.

It is instructive to relate our results to the cheap-talk literature. In Crawford and Sobel (1982) cheap-talk is only effective if interests are at least partially aligned. Dickhaut et al. (1995),

\footnotetext{
${ }^{22}$ We define lying aversion as a fixed cost incurred when sending a message that does not correspond to one's type (Ellingsen and Johannesson, 2004). It is interesting to note the fixed cost of lying required to induce truth-telling in MF and MF II is 9.31, almost double the surplus generated from trading an object. We omit a theoretical discussion of lying aversion, as it is straightforward to see that it leads to more market segmentation in our setting.

${ }^{23}$ Subjects who were sellers in the market game were chosen to be senders in the lying aversion task. One of the eight payoff pairs was randomly selected for payment. Subjects that did not have a unique switching point from message A to message B are dropped from the analysis (28\% in CF). Receivers only observed their own payoff, i.e. they never knew whether the sender was lying.

${ }^{24}$ All 20 periods are included in the regression. Robust standard errors are clustered on individuals. An issue with the lying aversion task is that senders may have different expectation about whether the receivers believe their message or not (Sutter, 2009). We elicited these beliefs and restrict attention to cases in which the sender believed that the receiver will follow the message ( $65 \%$ of the senders in $\mathrm{CF}$ ).
} 
Cai and Wang (2006) and Wang et al. (2010) test Crawford and Sobel (1982)'s model in the lab and observe behavior akin to the most informative equilibrium; see also Crawford (1998). The cheap-talk literature has so far primarily focused on bilateral situations. There is, however, no reason to believe that cheap-talk is less important in larger groups. This is illustrated by our results: while the interests of an isolated buyer-seller pair are fully opposed, sellers and buyers have partially aligned interests once they are integrated in a market set-up: both can benefit from market segmentation.

The theoretical literature on cheap-talk broadly supports our finding that the market segmentation equilibrium is more likely to be observed than pooling equilibria. In a pooling equilibrium, a seller would strictly prefer to communicate to be a low type if and only if she is indeed a low type. Farrell (1993) argues that such a message is credible, hence leading to separation 25 Chen et al. (2008) propose the NITS (no incentive to separate) criterion to select among cheap-talk equilibria. NITS requires that the lowest type (the type that no other type wants to mimic) weakly prefers the equilibrium outcome to credibly revealing her type, if she somehow could. It is apparent that babbling equilibria do not satisfy NITS in our setting: low quality sellers would strictly prefer to reveal their type to attract more buyers than in the pooled market. Both the symmetric and the asymmetric partially separating equilibria satisfy NITS. To see this, notice that low quality sellers in a partially separating equilibrium have the opportunity to reveal their quality by sending message $l$. The fact that some do not implies that they prefer the equilibrium outcome. We are not aware of any cheap-talk equilibrium selection criterion that would allow us to select among the symmetric and asymmetric partially separating equilibria 26

An alternative experimental design could have been used to examine some of the effects of market segmentation. Suppose that (1) sellers choose between two predetermined prices, say 3 and 17, and (2) buyers choose a submarket - now characterized by a price at which trade occurs. In this setting, sellers can commit to a price. Due to the frictions, low quality sellers still have an incentive to choose the lower price. In fact, there is no "babbling," because posted prices are binding. The setting examined in the experiment is richer: messages are non-binding and there are multiple equilibria, some of which mirror market breakdowns that are familiar from standard models of adverse selection. We find that cheap-talk is sufficient to help alleviate the adverse selection problem and no commitment on the part of the sellers is required.

Our experiment also speaks more generally to the literature on the efficiency of laboratory markets (e.g. Smith, 1962). Most experiments have employed posted offers markets or double auctions. Those are centralized institutions, because buyers and sellers observe all offers in the market. See for example Miller and Plott (1985) who show that quality separation is achieved if sellers have the possibility to invest in costly signals. Holt (1995) offers an excellent review. On of the first market experiments, conducted by Chamberlin (1948), studied a simple two-sided institution with decentralized negotiations. Chamberlin's subjects were allowed to roam freely around the room and negotiate contracts. He finds that the actual quantities traded exceed the

\footnotetext{
${ }^{25}$ See also the related cheap-talk criteria in Rabin (1990) and Matthews et al. (1991).

${ }^{26}$ De Groot Ruiz et al. (2015) propose a selection criterion (Average Credible Deviation) that takes into account the number of players who want to upset a given equilibrium as well as how much they would benefit from doing so. They demonstrate that this can be a powerful approach to reduce the number of equilibria. However, in the partially separating equilibria of our setting, there are no profitable deviations to another message: low types who send message $h$ lose when identifying themselves as a low type, and low types who send message $l$ lose when deviating to message $h$. As a consequence, the symmetric and the asymmetric partially separating equilibria satisfy the Average Credible Deviation criterion.
} 
equilibrium amount. In recent years, the theoretical literature has made considerable progress in understanding what features of decentralized markets are conducive or detrimental to efficiency. Lauermann (2013) provides a general approach to this question. To the best of our knowledge, there do not exist experiments complementing these insights. The experiment reported in this paper provides a first step in this direction, and the results strongly support the predictions of the decentralized market model.

The first-best outcome cannot be reached in situations that are impaired by adverse selection. This poses the question to what extent decentralized markets fall short of the constrained-efficient outcome. Our results demonstrate that an answer will crucially depend on the available communication opportunities. Moreover, the optimal decentralized market will often include some level of matching frictions. More theoretical and experimental research is needed to understand the efficiency properties of decentralized markets, and the role of cheap-talk in such environments.

\section{Acknowledgments}

It is a pleasure to thank Olivier Bochet, Pedro Dal Bó, Guillaume Fréchette, Jacob Goeree, Pablo Hernández-Lagos, Marc Möller, Nikos Nikiforakis and Joel Sobel for helpful comments. I also thank the advisory editor, three reviewers and seminar participants at Brown University and the Inaugural Winter Experimental Social Sciences Institute at New York University in Abu Dhabi. This project started at the University of Bern. This work was supported by the Swiss National Science Foundation [grant number 100018-143757]. 


\section{References}

AKeRLOF, G. A. (1970): "The market for lemons: Quality uncertainty and the market mechanism," The Quarterly Journal of Economics, 84, 488-500.

Blume, A., D. V. DeJong, Y.-G. Kim, And G. B. Sprinkle (2001): "Evolution of communication with partial common interest," Games and Economic Behavior, 37, 79-120.

Cadsby, C. B., M. Frank, and V. Maksimovic (1990): "Pooling, separating, and semiseparating equilibria in financial markets: Some experimental evidence," Review of Financial Studies, 3, $315-342$.

CAI, H. AND J. T.-Y. WANG (2006): "Overcommunication in strategic information transmission games," Games and Economic Behavior, 56, 7-36.

Chamberlin, E. H. (1948): "An experimental imperfect market," The Journal of Political Economy, 56, 95-108.

Charness, G. And M. Dufwenberg (2006): "Promises and partnership," Econometrica, 74, 1579-1601.

- (2010): "Bare promises: An experiment," Economics Letters, 107, 281-283.

- (2011): "Participation," American Economic Review, 101, 1211-1237.

Chen, Y., N. Kartik, And J. Sobel (2008): "Selecting cheap-talk equilibria," Econometrica, $76,117-136$.

Chen, Y. and R. W. Rosenthal (1996): "Asking prices as commitment devices," International Economic Review, 37, 129-155.

Crawford, V. (1998): "A survey of experiments on communication via cheap talk," Journal of Economic Theory, 78, 286-298.

Crawford, V. and J. Sobel (1982): "Strategic information transmission," Econometrica, 14311451.

Croson, R., T. Boles, and J. K. Murnighan (2003): "Cheap talk in bargaining experiments: Lying and threats in ultimatum games," Journal of Economic Behavior 63 Organization, 51, $143-159$.

De Groot Ruiz, A., T. Offerman, and S. Onderstal (2014): "For those about to talk we salute you: an experimental study of credible deviations and ACDC," Experimental Economics, 17, 173-199.

- (2015): "Equilibrium selection in experimental cheap talk games," Games and Economic Behavior, 91, 14-25.

Dickhaut, J. W., K. A. McCabe, and A. MukherJi (1995): "An experimental study of strategic information transmission," Economic Theory, 6, 389-403.

Ellingsen, T. And M. Johannesson (2004): "Promises, threats and fairness," Economic Journal, 114, 397-420. 
Erat, S. And U. Gneezy (2012): "White lies," Management Science, 58, 723-733.

FArrell, J. (1993): "Meaning and credibility in cheap-talk games," Games and Economic Behavior, $5,514-531$.

FARrell, J. And R. GibBons (1989): "Cheap talk can matter in bargaining," Journal of Economic Theory, 48, 221-237.

Fehr, E., H. Herz, And T. Wilkening (2013): "The lure of authority: Motivation and incentive effects of power," American Economic Review, 103, 1325-1359.

Fischbacher, U. (2007): "z-Tree: Zürich toolbox for ready-made economic experiments," Experimental Economics, 10, 171-178.

Forsythe, R., R. Lundholm, And T. Rietz (1999): "Cheap talk, fraud, and adverse selection in financial markets: Some experimental evidence," Review of Financial Studies, 12, 481-518.

Gneezy, U. (2005): "Deception: The role of consequences," American Economic Review, 95, 384-394.

Goeree, J. K., C. A. Holt, and T. R. Palfrey (2002): "Quantal response equilibrium and overbidding in private-value auctions," Journal of Economic Theory, 104, 247-272.

Goeree, J. K. And J. Zhang (2014): "Communication \& competition," Experimental Economics, $17,421-438$.

Holt, C. A. (1995): "Industrial organization: A survey of laboratory research," in Handbook of Experimental Economics, ed. by J. Kagel and A. Roth, Princeton University Press, 349-443.

Kawagoe, T. And H. TAKizawa (2009): "Equilibrium refinement vs. level-k analysis: An experimental study of cheap-talk games with private information," Games and Economic Behavior, $66,238-255$.

KIM, K. (2012): "Endogenous market segmentation for lemons," The RAND Journal of Economics, $43,562-576$.

Kim, K. AND P. Kircher (2015): "Efficient competition through cheap talk: the case of competing auctions," Econometrica, 83, 1849-1875.

Kreps, D. M. And R. Wilson (1982): "Sequential equilibria," Econometrica, 50, 863-894.

Lauermann, S. (2013): "Dynamic matching and bargaining games: A general approach," American Economic Review, 103, 663-689.

Lundquist, T., T. Ellingsen, E. Gribbe, and M. Johannesson (2009): "The aversion to lying," Journal of Economic Behavior \&3 Organization, 70, 81-92.

Matthews, S. A., M. Okuno-Fujiwara, and A. Postlewaite (1991): "Refining cheap-talk equilibria," Journal of Economic Theory, 55, 247-273.

Miller, R. M. And C. R. Plott (1985): "Product quality signaling in experimental markets," Econometrica, 53, 837-872. 
Mortensen, D. T. And C. A. Pissarides (1994): "Job creation and job destruction in the theory of unemployment," The Review of Economic Studies, 61, 397-415.

Nelson, P. (1974): "Advertising as information," Journal of Political Economy, 82, 729-754.

RABin, M. (1990): "Communication between rational agents," Journal of Economic Theory, 51, $144-170$.

SAmuelson, W. (1984): "Bargaining under asymmetric information," Econometrica, 52, 995-1005.

Satterthwaite, M. And A. Shneyerov (2007): "Dynamic matching, two-sided incomplete information, and participation costs: Existence and convergence to perfect competition," Econometrica, $75,155-200$.

Smith, V. L. (1962): "An experimental study of competitive market behavior," The Journal of Political Economy, 70, 111-137.

SutTer, M. (2009): "Deception through telling the truth?! Experimental evidence from individuals and teams," Economic Journal, 119, 47-60.

Tversky, A. AND D. KAhneman (1991): "Loss aversion in riskless choice: A reference-dependent model," The Quarterly Journal of Economics, 106, 1039-1061.

VAlley, K., J. MoAG, AND M. BAZERMan (1998): "A matter of trust: Effects of communication on the efficiency and distribution of outcomes," Journal of Economic Behavior \& Organization, $34,211-238$.

Valley, K., L. Thompson, R. Gibbons, and M. Bazerman (2002): "How communication improves efficiency in bargaining games," Games and Economic Behavior, 38, 127-155.

VANBerG, C. (2008): "Why do people keep their promises? An experimental test of two explanations," Econometrica, 76, 1467-1480.

Wang, J. T.-Y., M. Spezio, and C. F. Camerer (2010): "Pinocchio's Pupil: Using Eyetracking and Pupil Dilation to Understand Truth Telling and Deception in Sender-Receiver Games," The American Economic Review, 100, 984-1007.

\section{Appendix A. Proof of Observation 2}

In every (partially) separating equilibrium one message, say $l$, reveals a seller to be of the low type, i.e. we must have $\alpha(H)=0$ (see Kim, 2012). Consider a symmetric equilibrium with $1>\alpha(L)>0$. There is a positive probability that all low quality sellers send message $l$. Message $h$ is thus a profitable deviation, if a buyer's optimal offer for belief $n_{H} /\left(n_{H}+1\right)$ - the only belief consistent with equilibrium behavior - exceeds $c_{H}$ with positive probability (see footnote 11). Further, for $\alpha(L)=1$ to be part of a sequential equilibrium, there must exist a sequence of strictly mixed strategies which has as a limit point the strategies and beliefs (computed using Bayes' rule) observed in the candidate equilibrium. Sellers are anonymous. Thus, sequential equilibrium requires buyers to put a probability of $n_{H} /\left(n_{H}+1\right)$ on the high quality, if observing the off-equilibrium behavior in which his matched seller sends message $h$ and there are $n_{H}+1$ messages $h$. Hence, low quality sellers have a profitable deviation to send message $h$ if $\alpha(L)=1$. 